\title{
Expanding and Improving Our Library's Virtual Chat Service
}

\author{
Discovering Best Practices when Demand Increases \\ Parker Fruehan and Diana Hellyar
}

\begin{abstract}
With the onset of the COVID-19 pandemic and the ensuing shutdown of the library building for several months, there was a sudden need to adjust how the Hilton C. Buley Library at Southern Connecticut State University (SCSU) delivered its services. Overnight, the library's virtual chat service went from a convenient way to reach a librarian to the primary method by which library patrons contacted the library for help. In this article, the authors will discuss what was learned during this time and how the service has been adjusted to meet user needs. Best practices and future improvements will be discussed.
\end{abstract}

\section{BACKGROUND}

The Buley Library started using Springshare's LibChat service in January 2015. The chat service was accessible as a button in the header of all the library webpages, and the wording would change depending on the availability of a librarian. At Buley Library, the chat service is only staffed by our faculty librarians. There were other chat buttons on various individual LibGuides for either specific librarians or for the general library chat. Chat was monitored at the Research \& Information Desk by the librarian on duty. The first librarian of the day would log into the shared chat account on the reference desk computer. While each librarian had their own account, using a shared account meant that the librarians could easily hand off a chat interaction during a shift change.

While the reference desk was typically busy, librarians would only receive a small number of chats per day. Between 2015 and 2019, the library saw an average of 250 chats per year. Due to the low usage, there was little focus on LibChat training for librarians. For more complicated questions, librarians would often recommend that chat users call, email, or schedule an in-person appointment. Since LibChat was only monitored while librarians were at the reference desk, it was easy to let it become a secondary mode of reference interaction, particularly if there was a surge of in-person reference questions at any given time.

Due to the COVID-19 pandemic, the library quickly shifted from mostly in-person to solely online services. Suddenly, LibChat was the virtual reference desk and the main mode of patron interaction. Despite this change in how the library interacted with the campus, there was only a slight increase in chat usage in the first two months of the closure. In April 2020, we started to explore our options with LibChat in the hopes of increasing visibility and usage.

Parker Fruehan (fruehanp1@southernct.edu) is Assistant Librarian, Hilton C. Buley Library, Southern Connecticut State University. Diana Hellyar (hellyard1@southernct.edu) is Assistant Librarian, Hilton C. Buley Library, Southern Connecticut State University. (C) 2021. 


\section{EVALUATING CHAT WIDGET OPTIONS}

\section{Considering Technical Implementation}

The publicly accessible chat interface is made available completely within a webpage, requiring no clients, external applications, or plugins to make it functional. Springshare calls this component the LibChat widget, and provides a prepackaged set of website code necessary to create the chat interface. Within the LibChat system there are a few options for widget placement and presentation. At the time of writing, Springshare offers four widget types in its LibChat product: in-page chat, button pop-out, slide-out tab, and floating. ${ }^{1}$ When the service is offline, the system replaces the chat interface with a link to library FAQs and the option to submit a question for follow-up. At Buley Library, prior to the COVID-19 pandemic shutdown, the button pop-out was the main widget type used to enter a chat session (see fig. 1).

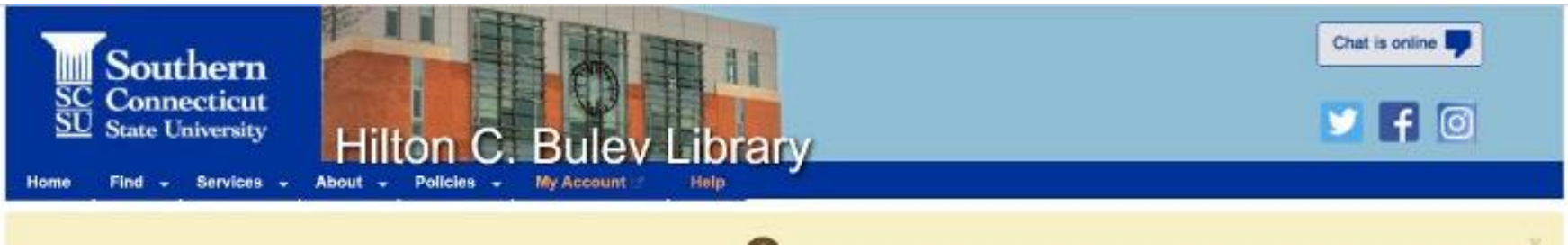

Figure 1. Previous library website header with chat pop-out button in upper right-hand corner.

The pop-out button works by opening a separate pop-up window with the chat interface. This allows the user to navigate to other pages in the previous window without disconnecting from the session. One challenge to the pop-up window method is that many web browsers block pop-up windows by default, requiring a user to recognize and override this setting.

Another option used mainly on librarian profiles and subject guides is the in-page chat, which embeds the chat interface directly on an existing webpage. Many times, these chat widgets are connected to a particular user rather than the queue monitored by all librarians. The user will interact with the chat operator in this dedicated section of the webpage. If a user navigates to a different page in the same window or tab it will disconnect from the chat session.

These widget options are easiest when considering web design expertise and time commitment involved in implementation. Both the button pop-out and in-page chat can be accomplished with a user having access to a What You See Is What You Get, or WYSIYG, editor on the webpage and the ability to copy and paste a few lines of HTML code. It does not require any custom <script> elements to be placed in the page $<$ head $>$ or footer area.

\section{Choosing the Floating Widget}

When the library shifted to all virtual services, there was concern that the chat button could easily be missed by library patrons. It was decided at this point to investigate alternative options to invite patrons to chat with librarians. The floating chat widget was chosen as the best option and was integrated into the website during a theme update in May 2020.

The floating chat widget was made widely available to Springshare LibChat users in $2017 .{ }^{2}$ This widget operates by placing a chat icon at the bottom right of a webpage. This icon remains visible in this location while users scroll down a page. Another option is to implement this icon as a proactive widget which displays a message to users after a set number of seconds to invite them to start a chat session (see fig. 2). 


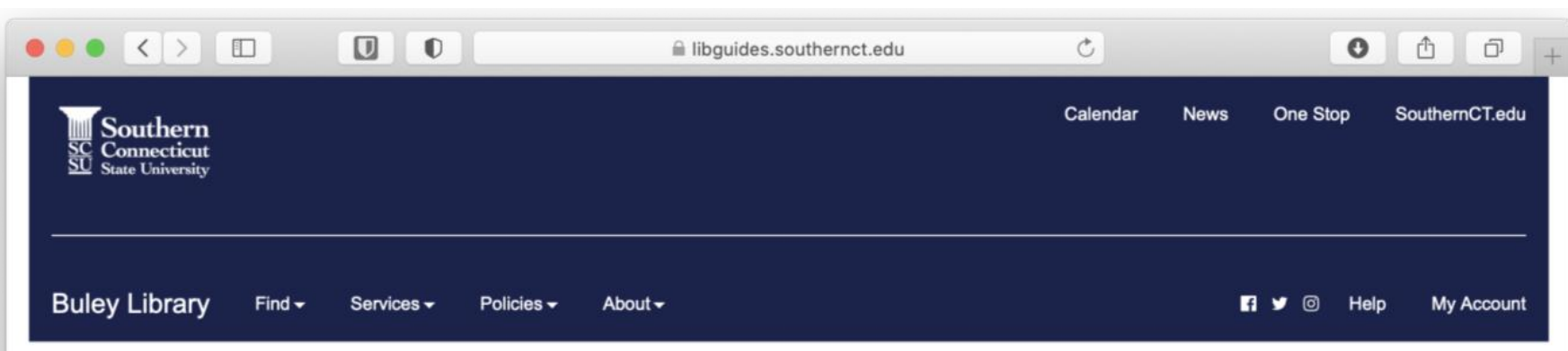

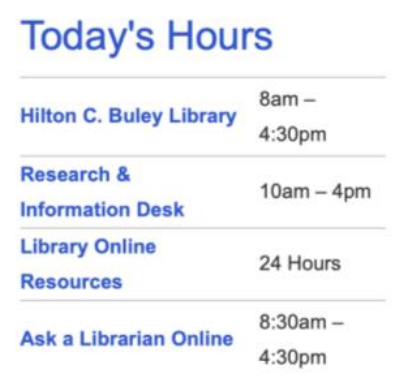

Librarian Chat

Reserve a Study Room

\section{Getting started}

Library FAQs

Borrowing \& Returning Materials

Instructor Resources

Holn \& Tutoriale

\section{SouthernSearch - Find e-Books and Articles}

\section{SouthernSearch}

Search for books, videos, articles, and more:

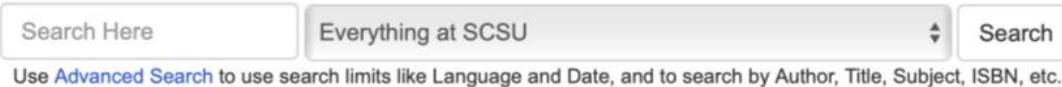

Use Advanced Search to use search limits like Language and Date, and to search by Author, Title, Subject, ISBN, etc.

\section{Find a Database}

Search for Journals

Find EBSCO Articles

Search Google Scholar

Search Library Website
Do you need help?

A librarian is online ready to help.

\section{Chat Now No Thanks}

Research and Information

Figure 2. Floating chat widget on the redesigned library homepage with the proactive setting enabled (pop-up modal) to invite users to begin a chat. A pop-out button is also on the library homepage for patrons who were accustomed to the previous version.

Implementing this type of widget requires an administrator level of access to the website Content Management System if it is to be implemented across an entire website. A single <script $>$ tag in the $<$ head $>$ section of the site template will activate it across an entire site.

The floating chat widget is a common feature widely seen in the business world and on retailer websites. The hesitation in implementing this type of widget was that it would be perceived by patrons as intrusive or annoying. However, one study reported finding that college students found it useful. ${ }^{3}$ Additionally, several other libraries have written previously about their success in implementing a proactive chat widget. ${ }^{4}$ It was decided that the library would implement this proactive chat widget on a trial basis and then evaluate the outcome as to whether to continue or not.

Shortly after, it was decided to add another proactive chat widget to SouthernSearch, the library's discovery platform, built on Ex Libris Primo (see fig. 3). The Primo New UI, built on NodeJS, is more complex to implement as it requires building a JavaScript function to insert the chat widget 
script code into the application for NodeJS to render on the front-end. This process is well documented by Laura Guy of the Colorado School of Mines. ${ }^{5}$

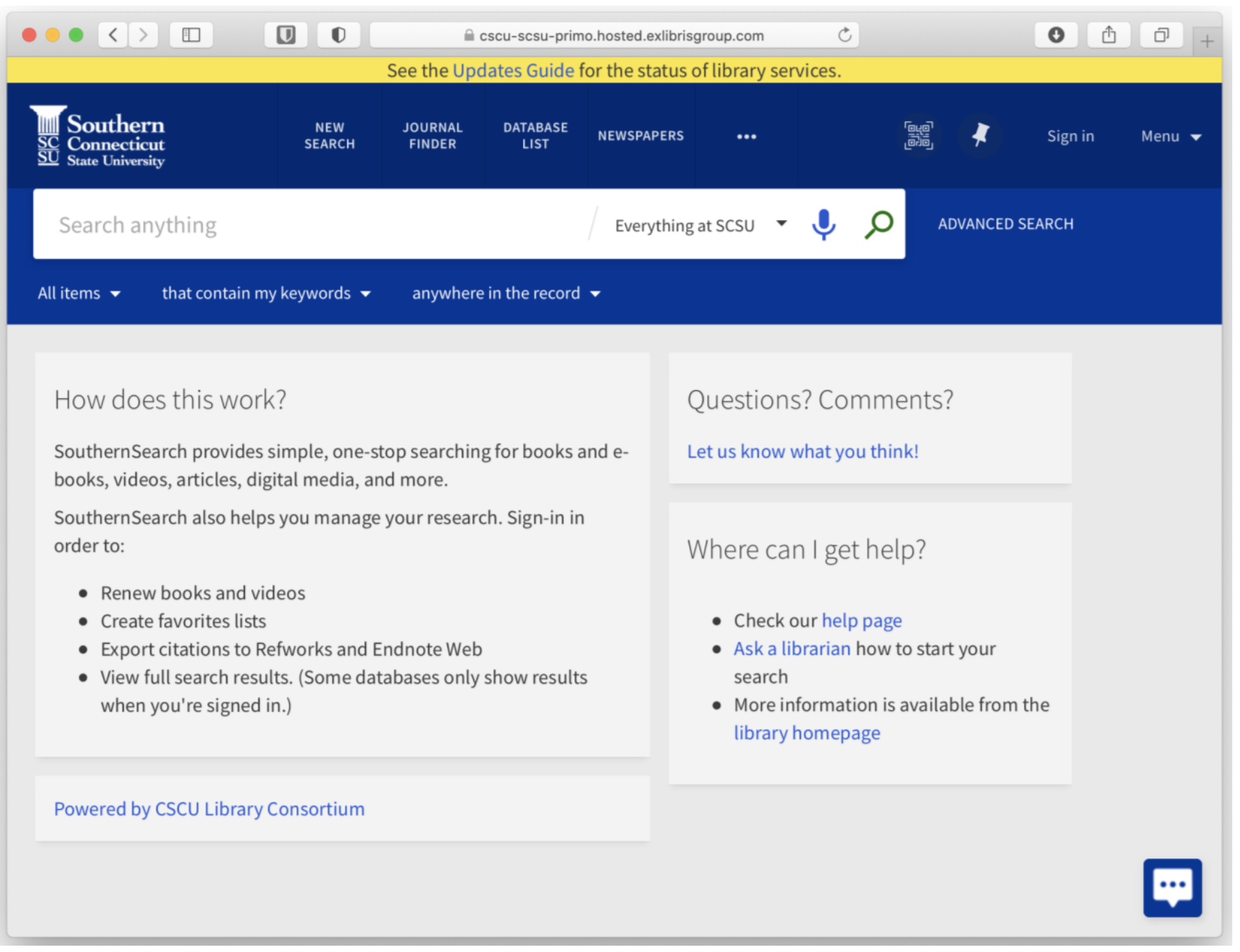

Figure 3. Embedded chat widget in SouthernSearch discovery platform. The pop-up modal is hidden in this view.

\section{LibChat in Action}

In Active Chats

The Ask a Librarian Chat became the library's virtual reference desk when the university closed its campus in March 2020 due to the COVID-19 pandemic. With the new focus on chat, the librarians decided it was time for a refresher on LibChat. Training was also necessary due to an update to the librarian LibChat dashboard. A virtual training session was held to show librarians how to use the new dashboard and to remind everyone how best to use chat since it was infrequently used prior to closing in-person services. The training was recorded, and a link was provided to everyone so librarians could watch the training again as needed.

The LibChat widget change caused a huge increase in daily chat numbers. The library received 47 chats in April with the chat button. The total spiked to 160 in May with the floating chat widget. Historically, there is a decrease in both virtual and in-person reference interactions during the month of May. Librarians were answering more chats than ever before. However, some librarians 
still had questions or technical troubles that did not get asked until after a chat ended. There was a need for a place to address these questions ahead of time so answers could be provided at the point of need. In response, a LibChat Best Practices guide was created soon after the widget change to have a place to house tips for effective chat interactions and for quick troubleshooting answers. The best practice guide was well received by librarians; however, it was underutilized. LibChat administrators hoped to be able to add a link to it directly within the dashboard for quick reference if librarians had an issue during a live chat, but they were unable to do so. The librarians added new canned messages to increase efficiency and consistency among common patron needs. Canned messages are commonly used prewritten statements that can be utilized by all librarians on chat. They can be created by an administrator to be used by any librarian and can be easily added to any active chat. For example, librarians created messages for bookstore contact information, how to request electronic delivery of journal articles, and the library's hours.

\section{Privacy Considerations}

The library's chat system is capable of capturing data that comprises personally identifiable information (PII) for a patron. An intentional decision was made to limit this collection as much as possible in keeping with the principles of ALA's stance on patron privacy in the Library Bill of Rights, which as interpreted says:

The right to privacy includes the right to open inquiry without having the subject of one's interest examined or scrutinized by others, in person or online. Confidentiality exists when a library is in possession of personally identifiable information about its users and keeps that information private on their behalf. ${ }^{6}$

The chat login form asks a patron for information before starting a chat; that information can include name, contact information (such as email or phone numbers), and up to three customized questions. Additionally, the system automatically captures the referrer URL and the user's public IP address, browser, and operating system. While it would be helpful to have more information up front, this could lead to the collection of a wealth of PII.

With these concerns in mind, it was decided to make PII such as name, email address, and phone numbers an optional entry. While knowing a name and email address is useful when the librarian would like to follow up on a question or if a chat session is unintentionally disconnected, it is not necessary. The librarian may request this information later in the chat if needed.

\section{HANDLING HARASSMENT AND INAPPROPRIATE BEHAVIOR}

In June, one chat patron caused an immediate change in the operation of LibChat at the library. On this day, a librarian answered an incoming chat, and a hostile patron threatened the librarian. Before the situation could be addressed, another question from an anonymous patron came into the queue. A second librarian, who happened to be one of this article's authors, claimed the chat despite being aware of the situation and suspecting this was the same difficult patron. It began as a normal interaction but eventually they became inappropriate. The librarian warned the patron multiple times before finally ending the chat and blocked their IP address. In response, the patron left an inappropriate comment on the ratings and comments survey after the chat interaction finished.

This one patron interaction made the librarians realize that they were vulnerable to harassment and other hostile behavior. Changes were made to help create a safe environment for librarians 
and patrons. First, training and instructions were provided so every librarian knew how to ban a user's IP address. It was made clear that those IP addresses could be reinstated if a mistake was made. The list is checked on occasion to determine if any decision needed to be reverted or if a university IP address was inadvertently banned. This is especially important if one bans the IP address assigned to the university edge router, a critical network device from which all campus HTTP traffic originates. This could block all users on campus from accessing LibChat.

Additionally, some librarians also chose to change their names from the default option which is full first and last name. Many changed their display name, using a combination of their first names, and subject liaison specific job titles. A decision was also made to turn off the chat rating and comment survey. It was not useful for the library's own assessment purposes as most chat interactions were left unrated. Leaving it in place could lead to more inappropriate behavior as comments can be left by a patron even after being banned.

Most importantly, the librarians created a virtual reference policy. While there was an existing general reference policy in place, it did not focus on, nor specifically mention, online conduct. Librarians agreed that it was time to create an additional policy since the increase in usage identified new concerns. The policy gave librarians grounds to ban patrons if needed, informing them that inappropriate conduct was against the virtual reference policy, and disclosed the librarian's right to report inappropriate behavior to campus authorities. A canned message was created to allow librarians to quickly inform a patron before banning the IP address and ending the chat. The message warns the patron their behavior violates the virtual reference policy and links to the library's Research \& Instruction Policies page where the policy is included.

In the beginning of the Fall 2020 semester students returned to school, both on campus and virtually. As shown in figure 1, there was a huge spike in chat questions at the beginning of the semester. Typical questions included those about borrowing textbooks, using study rooms, and research questions. Librarians could sometimes tell if chats were from SCSU students or employees if the patron provided their school email address.

Librarians started seeing another interesting trend with the referrer URL. It was noticed that subject guides see more chat patrons who provide non-university email addresses or provide no contact information. When asked, patrons respond they were not affiliated with SCSU. It is suspected that non-SCSU patrons find the library's subject guides through a search engine and while exploring the page the floating chat prompts them to chat with a librarian. The floating chat widget has helped to inform us about outside traffic to some of our guides. This has encouraged the library to take a more proactive approach to LibGuide maintenance among subject librarians, especially the small number of guides with heavy chat traffic. 


\section{OBSERVING PATRON USAGE}

\section{Monthly Breakdown of Chats}

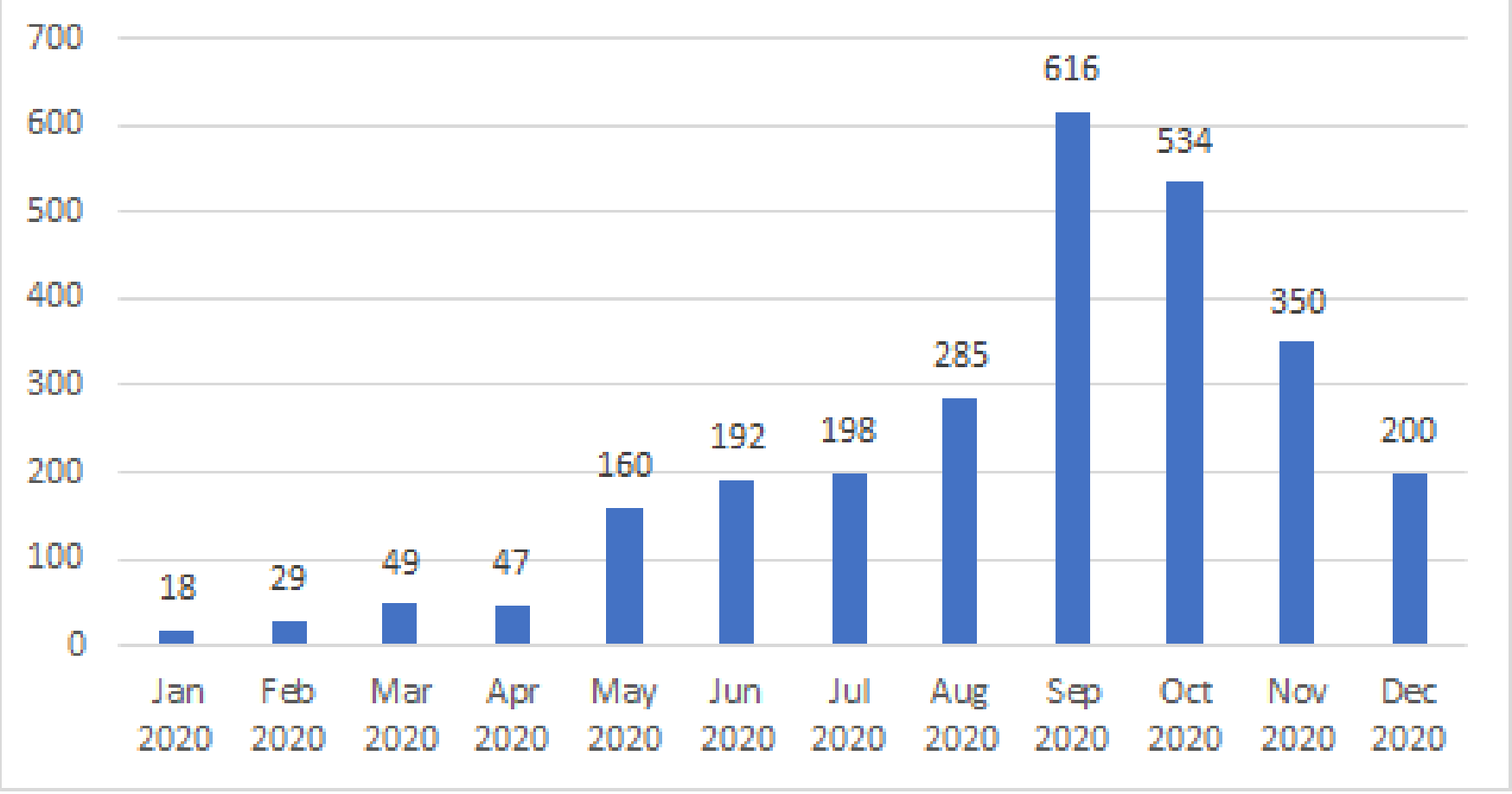

Figure 4. Total number of chats per month from January to December 2020.

\section{Best Practices}

The lessons learned from the increased chat usage have helped shape a better approach to virtual reference services and create better experiences for the librarians and patrons using the service. With that, here are some considerations and recommendations to expand virtual reference or chat services at other libraries:

- Use a persistent chat widget with pop-up notifications on all library pages to remind patrons that immediate help is available.

- Consider patron privacy when making decisions about chat settings.

- Have policies in place that cover virtual services, such as chat, that includes language on harassment and other inappropriate behavior.

- Use the policy language for a canned message so librarians can reply quickly if there is an issue.

- Be prepared for non-university affiliated patrons using chat services, especially from subject guides easily found through search engines.

\section{WHAT'S NEXT AT BULEY LIBRARY}

There are a few anticipated changes for the Buley Library chat service in the future. The library's student advisory board praised the library chat, sharing they found it to be a great way for students to be able to contact librarians for help. However, they did suggest the library consider the branding of the service. Their recommendation was to make it clear before a patron starts an 
interaction that a real SCSU librarian would be answering the chat. They felt as though students may think that the answerer would be a chat bot or from a call center and not a real librarian that works for the school.

Additionally, librarians will re-evaluate chat coverage schedules based on usage data. The current schedule is based on in-person desk coverage. However, in-person historical statistics do not translate well to online reference services; busy periods for in-person reference services may not be the case for the same period online. The trend appears to show that weekend chat transactions exceed those of in-person transactions during the same period a year previously. Noticing this trend, chat scheduling may need to be adjusted to better align demand with librarian availability.

These adjustments could include longer shifts scheduled less frequently rather than daily hourlong shifts. Chat allows for more multitasking, so a longer shift may be preferable. It might help the librarian adjust their own schedule in preparation for a longer chat shift. Chat coverage may need to be evaluated again when the library eventually goes back to operating an in-person reference desk. One pressing question is, will chat demand go back to pre-COVID levels, or will it remain high when an in-person reference desk returns? While an in-person reference desk is likely to come back in the future, if chat traffic remains high, a separate schedule may be needed for chat in addition to the reference desk, so the same person is not operating both at the same time.

\section{CONCLUSION}

It may never be known if the increase in chat volume came from the widget updates or was due solely to the pandemic, but it is likely a bit of both. Increased chat volume seems to correlate strongly with implementing the floating chat widget, even though there was already an increase due to the effects of the pandemic shutdown. It is planned to look in depth at all available chat data and compare it to in-person reference statistics. Another area for further research is the textual analysis of chat transcripts to find trends and make recommendations for greater effectiveness.

\section{ENDNOTES}

1 "Springboard Tutorials: Create LibChat Widgets," Springshare Help Center, accessed January 11, 2021, https://ask.springshare.com/springboards/faq/1880.

2 “LibAnswers 2.15 Update-Redesigned Chat Widgets!," Springshare Blog, July 6, 2017, https://blog.springshare.com/2017/07/06/libanswers-2-15-update/.

${ }^{3}$ Bonnie Brubaker Imler, Kathryn Rebecca Garcia, and Nina Clements, "Are Reference Pop-up Widgets Welcome or Annoying? A Usability Study," Reference Services Review 44, no. 3 (January 1, 2016): 282-91, https://doi.org/10.1108/RSR-11-2015-0049.

${ }^{4}$ Jan H. Kemp, Carolyn L. Ellis, and Krisellen Maloney, "Standing By to Help: Transforming Online Reference with a Proactive Chat System," Journal of Academic Librarianship 41, no. 6 (November 1, 2015): 764-70, https://doi.org/10.1016/j.acalib.2015.08.018; Michael Epstein, "That Thing Is So Annoying: How Proactive Chat Helps Us Reach More Users," College \& Research Libraries News 79, no. 8 (2018), https://doi.org/10.5860/crln.79.8.436.

${ }^{5}$ Laura Guy, "Embedding SpringShare LibChat Widget into the Primo NU," Ex Libris Developer Network Tech Blog, updated December 17, 2018, 
https://developers.exlibrisgroup.com/blog/embedding-springshare-libchat-widget-into-theprimo-nu/.

6 "Privacy: An Interpretation of the Library Bill of Rights," American Library Association, amended June 24, 2019, https://www.ala.org/advocacy/intfreedom/librarybill/interpretations/privacy. 